\title{
Capacitor Location and Size Determination to Reduce Power Losses of a Distribution Feeder in Lao PDR
}

\author{
K. Tilakul, P. Buasri, A. Kaewrawang and J. Triyangkulsri
}

\begin{abstract}
This paper presents the capacitor bank location and size to reduce the total power losses and its cost by optimizing location and size of the capacitor bank in the distribution feeder in Lao PDR. The voltage drop and power loss before and after installing the capacitor were compared in this work. The result showed better voltage profiles and power losses of the distribution system could be improved by using the proposed method with 9 and 37-buses in Vientiane province. The proposed method can be a benefit in the distribution feeder analysis for planning and operation in Lao PDR.
\end{abstract}

Index Terms-Distribution feeder, capacitor, power loss, minimum cost.

\section{INTRODUCTION}

A major problem in a power distribution system is a voltage drop due to high-load, very long power distribution systems, and rapid load growth in a radial network [1], [2]. The power distribution system of Vientiane province in Lao PDR has three operation voltages $22 \mathrm{kV}, 25 \mathrm{kV}$, and $34.5 \mathrm{kV}$; but only the $22 \mathrm{kV}$ distribution feeder level has a high voltage drop under the heavy load [3]. Consequently, it provides inefficient service to its customers. Methods to solve this problem have been studied such as local capacitor variation [4], loss reduction by means of capacitor installations [5], adding a distribution generator [6], enhancing three-phase balancing of distribution[7], building new substations, building new feeders and load balancing among feeders [8] or integrating of photovoltaic generation to the distribution system[9]. Capacitor location is a common method to reduce power losses and maintain voltage under limitation [10] because of low cost and investment, simple installation and simple equipment to build a new capacitor.

In this paper, analytical techniques have been performed to determine the capacitor location and size for minimization of total power losses and cost reduction in the distribution feeder. Its location and size can be determined effectively by using load flow - a piecewise linear objective and optimization technique - a quadratic form. We also show the losses for a bus relative to losses in the bus.

In Section II, problem formulation and implementation will be discussed for $23 \mathrm{kV}$-distribution feeder of 9-bus and $22 \mathrm{kV}$ distribution feeder of 37-bus in Lao PDR. The methodology in this work is given in section III.

The results and discussion from calculation and simulation before and after installation of capacitor bank are discussed in the Section IV and finally conclusion in Section V.

Manuscript received September 26, 2011; revised December 12, 2011.

The authors are with the Electrical Engineering, Khon Kaen University, Thailand; (e-mail: kham.ley@gmail.com; e-mail: panbua@kku.ac.th; e-mail: arkokm2004@hotmail.com; e-mail: jittipatht@gmail.com)

\section{Problem Formulation AND Power Loss Reduction}

The optimization technique and computer program are proposed for implementation of load flow in Lao PDR compared with the Plant Growth Simulation Algorithm (PGSA) [11] and fuzzy logic [12]. The details of problem formulation and power loss reduction are mentioned in Sub-section A and B, respectively.

\section{A. Problem Formulation}

The objectives of the capacitor location are to reduce the power loss and keep voltages within the prescribed limits with minimum cost. The total power loss, $P_{\text {Tloss, }}$ is given by

$$
P_{\text {Tloss }}=\sum_{i=1}^{N b} P_{\text {Loss }(i, i+1)}
$$

where $i$ is the bus number and $N b$ is the total number of buses. Considering investment, there is a finite number of standard capacitor sizes that are integer multiples of the smallest size, $Q_{j}^{C}$. The cost per kVAr varies from one size to another and the large sizes are cheaper than smaller ones. Let the maximum permissible capacitor size be limited to [13]:

$$
Q_{\max }^{C}=L \times Q_{0}^{C}
$$

where $Q_{0}^{C}$ is the smallest capacitor size in Table I. The $L$, which is an integer is derived from dividing the maximally allowed capacitor size of $Q_{\max }^{C}$ for this feeder on the smallest value of $Q_{0}^{C}$ at each selected location. There are $L$ sizes to choose from $k_{1}^{C}, k_{2}^{C}, \ldots, k_{L}^{C}$ as the corresponding capital investment per kVAr. The optimized location and size for these capacitor banks were determined such that they minimize the minimum cost of system under study. The objective function used for capacitor allocation is:

$$
\text { Min. } f=\sum_{j}^{k} K_{j}^{C} Q_{j}^{C}+K_{S} \sum_{i=1}^{N b} P_{\text {Loss }(i, i+1)}
$$

where $K \mathrm{~s}$ is the cost per power loss ( $\$ \mathrm{~kW} /$ year) and $j=1,2$, $3, \ldots, k$ represents the selected buses. The objective function

(3) to be minimized is subject to:

$$
\begin{gathered}
V_{i, \text { min }} \leq V_{i} \leq V_{i, \max } \\
Q_{i, \text { min }} \leq Q_{i} \leq Q_{i, \max }, i=1,2,3, \ldots, N b .
\end{gathered}
$$

For the test feeder, $K s$ is selected to be U.S. $\$ 168 / \mathrm{kW}$ [9], and the voltage limits are $V_{\min }=0.9000$ p.u. and $V_{\max }=$ 1.1000 p.u. The $Q_{i, \min }$ and $Q_{i, \max }$.are the minimum and 
maximum reactive power, respectively, at the bus $i$. The commercially available capacitor sizes with U.S.\$/kVAr are used in the analysis.

\section{B. The Power Loss Reduction}

In the proposed method, the optimal sizes and placements of the capacitors are ones that minimize (3), satisfy (4), (5), and (6) i.e. give the minimum total power losses, minimum cost, and satisfy the voltage constraint.

$$
P_{\text {TLoss }}^{(K+1)} \leq P_{\text {TLoss }}^{(K)}
$$

where $k+1$ is the case after the capacitor location and $k$ is the case before the capacitor location. The solution from program of proposed method can be summarized as follows:

Step 1: Perform the load flow solution for the original feeder to get the total power loss and other necessary data.

Step 2: Putting $Q_{j}^{C}$ equal to the smallest value in Table I at the far end bus (i.e. bus no. n) from the substation and perform the load flow.

Step 3: Compare the total power losses in each bus of the feeder that resulted from step (2) with that resulted from step (1).

Step 4: If the total losses in each bus are less than or equal to that of the prior case then try with the next value of $Q_{j}^{C}$ from 27 standard values of $Q_{j}^{C}$, perform the load flow, and compare with the total power losses as in step (3). Then compare it with the total losses that resulted when the prior value of $Q_{j}^{C}$ was placed.

Step 5: Repeat step (4) with the different values of $Q_{j}^{C}$ placed at this bus until reaching the optimal value of $Q_{j}^{C}$ i.e. minimize (3), satisfy (4), (5) and (6).

Step 6: If the total loss in any system of the feeder is higher than that of the prior case then remove the value of $Q_{j}^{C}$ and put the prior value of $Q_{j}^{C}$.

Step 7: With optimal $Q_{j}^{C}$ placed at the far end bus, perform the load flow and check the voltage profile if $(0.9000$ $\leq V$ bus $\leq 1.100)$ then stop otherwise to try with the next bus i.e. bus no $(n-1)$ and so on until $V_{\min } \geq 0.9000$.

\section{Methodology}

In the distribution feeder of the Lao PDR, the improvement of loss reduction is achieved by testing the load and impedance data. The impedance, real power and reactive power at the load of the radial distribution system are calculated. Simulations are run under 2 cases before and after installing a capacitor at each bus. The capacitor size and location problem are solved in the flow chart shown in Fig. 1.

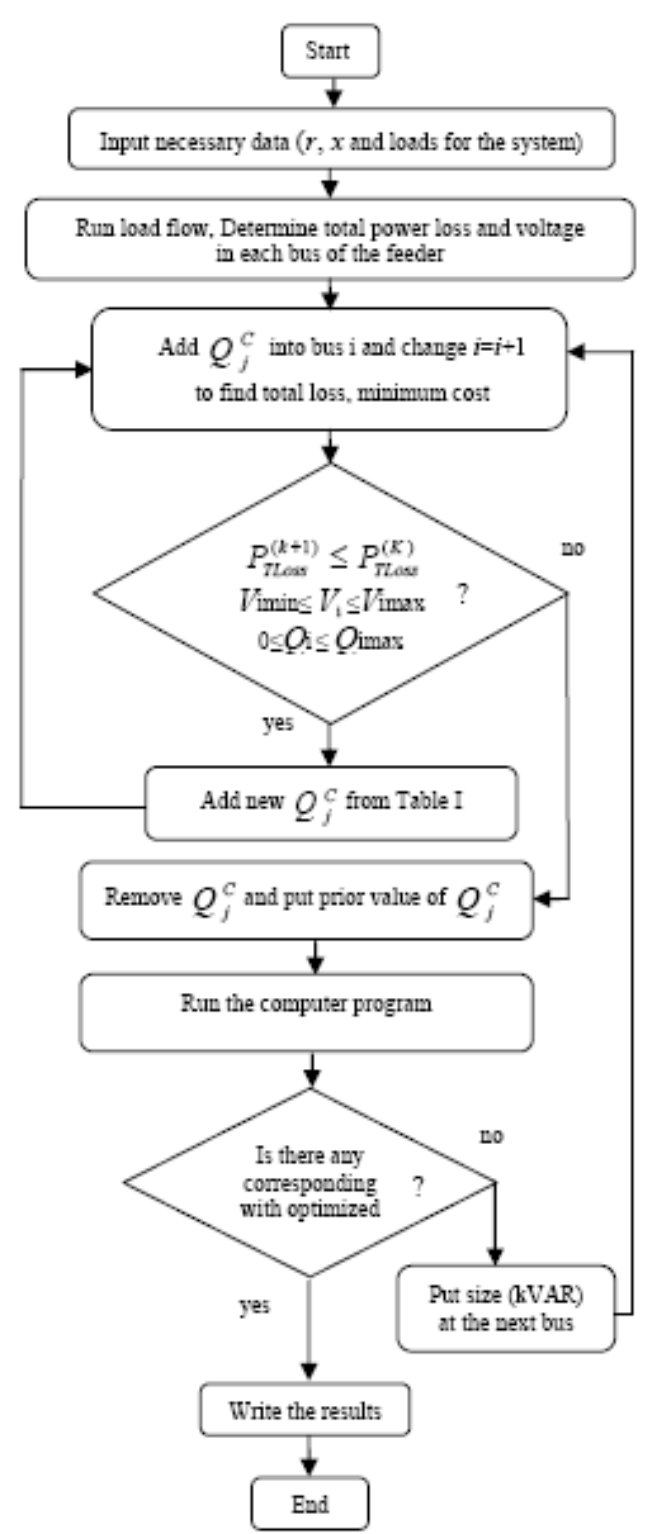

Fig. 1. Flowchart for the operation method.

\section{RESUlts AND DisCUSSION}

\section{A. Testing of the Proposed Methods: 9-Bus}

A radial distribution feeder was used for tests as shown in Table 1. Fig. 2 shows the loads and feeder line constants.

The 9-bus radial distribution feeder [13] was applied as the test feeder. The rated voltage was $23 \mathrm{kV}$. The load data and feeder-line parameters of the single line diagram for the system are shown in Fig. 2. By applying the load flow program on this feeder before compensation, the cost function and the total power losses were U.S. \$31,675 and $783.8 \mathrm{~kW}$, respectively. The maximum and the minimum bus voltage magnitudes were 0.9929 and 0.8375 p.u., respectively, where the voltage of the substation (bus number 0 ) was assumed to be 1 p.u., thus we generally obtained $0.8375 \leq V_{\mathrm{i}} \leq 1.0000$ p.u. 


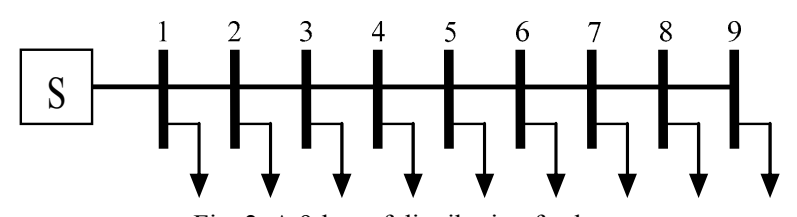

Fig. 2. A 9-bus of distribution feeder.

The 27 possible choices of capacitor sizes along with corresponding annual cost are given in Table I.

TABLE I: CAPACITOR SIZES AND COST [13]
\begin{tabular}{|c|c|c|c|c|c|c|c|}
\hline $\mathrm{j}$ & 1 & 2 & 3 & 4 & 5 & 6 & 7 \\
\hline $\mathrm{Q}_{\mathrm{j}}^{\mathrm{c}}$ & 150 & 300 & 450 & 600 & 750 & 900 & 1050 \\
\hline$\$ / \mathrm{kVAr}$ & 0.500 & 0.350 & 0.253 & 0.220 & 0.276 & 0.183 & 0.228 \\
\hline $\mathrm{j}$ & 8 & 9 & 10 & 11 & 12 & 13 & 14 \\
\hline $\mathrm{Q}_{\mathrm{j}}^{\mathrm{c}}$ & 1200 & 1350 & 1500 & 1650 & 1800 & 1950 & 2100 \\
\hline$\$ / \mathrm{kVAr}$ & 0.170 & 0.207 & 0.201 & 0.193 & 0.187 & 0.211 & 0.176 \\
\hline $\mathrm{j}$ & 15 & 16 & 17 & 18 & 19 & 20 & 21 \\
\hline $\mathrm{Q}_{\mathrm{j}}^{\mathrm{c}}$ & 2250 & 2400 & 2550 & 2700 & 2850 & 3000 & 3150 \\
\hline$\$ / \mathrm{kVAr}$ & 0.197 & 0.170 & 0.189 & 0.187 & 0.183 & 0.180 & 0.195 \\
\hline $\mathrm{j}$ & 22 & 23 & 24 & 25 & 26 & 27 & -- \\
\hline $\mathrm{Q}_{\mathrm{j}}^{\mathrm{c}}$ & 3300 & 3450 & 3600 & 3750 & 3900 & 4050 & -- \\
\hline$\$ / \mathrm{kVAr}$ & 0.174 & 0.188 & 0.170 & 0.183 & 0.182 & 0.179 & -- \\
\hline
\end{tabular}

The results of the proposed method are shown in Table II compared with Plant Growth Simulation Algorithm (PGSA) [11] and Fuzzy Logic [12]. The results for this feeder are summarized in Table II.

TABLE II: THE COMPARISON OF RESUltS With [11], AND [12] IN CASE OF 9-BUS.

\begin{tabular}{|c|c|c|c|c|}
\hline & \multirow{2}{*}{$\begin{array}{c}\text { Without } \\
\text { Items }\end{array}$} & \multicolumn{3}{|c|}{ With Capacitor Bank } \\
\cline { 3 - 5 } & Bank & PGSA & $\begin{array}{c}\text { Fuzzy } \\
\text { Logic }\end{array}$ & $\begin{array}{l}\text { Proposed } \\
\text { Method }\end{array}$ \\
\hline Max.voltage in P.U & 0.9929 & 0.9991 & 1.0070 & 1.0003 \\
\hline Min.voltage in P.U & 0.8375 & 0.9010 & 0.9003 & 0.9002 \\
\hline Total loss in (kW) & 783.771 & 694.930 & 686.000 & 682.753 \\
\hline Total cost \$ & 131,675 & 118,340 & 117,035 & 116,560 \\
\hline Loss reduction (\%) & 0 & 11.330 & 12.388 & 12.889 \\
\hline
\end{tabular}

Table II shows the results of the feeder 9-bus. It was observed that the total power loss for the feeder was 682.753 $\mathrm{kW}$ and loss reduction was $12.889 \%$ on total annual cost before and after compensation. It was therefore less than that of the total power loss. The fixed cost (the cost of the installed capacitors only) was also less than that of the proposed method. Thus, the proposed method offers more cost saving and more loss reduction of a distribution feeder. The voltage profile for the proposed method was close to that of the 9-bus as shown in Table II.

\section{B. The 37-bus in Lao PDR}

The distribution feeder in Vientiane province has four sub-feeders of the substation. For justified conclusions support, the proposed method was applied to 37-bus radial distribution feeder. The distribution feeder in Lao PDR is under in base of $22 \mathrm{kV}, 16 \mathrm{MVA}$ of the substation. The load data and feeder-line parameters of the single line diagram for the system are shown in Fig. 3. Before compensation, the cost was U.S. \$20,258, which was based on the previously defined cost function, the total power loss was $120.589 \mathrm{~kW}$, the voltage limit in p.u. was $0.9427 \leq V_{1} \leq 0.9944$.

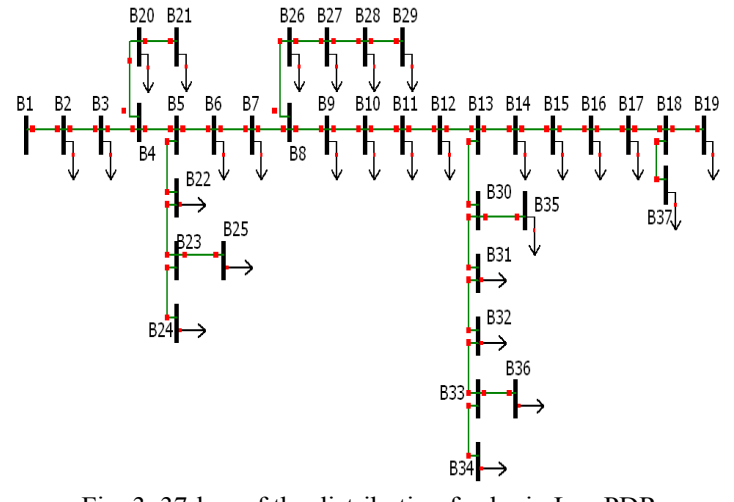

Fig. 3. 37-bus of the distribution feeder in Lao PDR

The results were within possible choices of capacitor sizes and cost as shown in Table I.

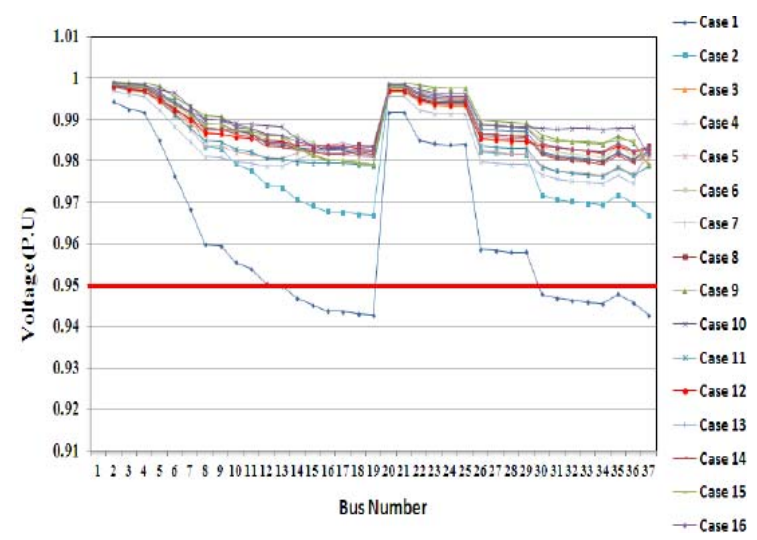

Fig. 4. Voltage profile before and after C-Bank allocation are 16-cases of the 37-bus

TABLE III: MAXIMUM Voltage AND Minimum VOLTAGE ARE 16-CASES OF THE 37-BUS

\begin{tabular}{|c|c|c|}
\hline Case & Max.Voltage in P.U & Min.Voltage in P.U \\
\hline 1 & 0.9944 & 0.9427 \\
\hline 2 & 0.9983 & 0.9668 \\
\hline 3 & 0.9978 & 0.9792 \\
\hline 4 & 0.9971 & 0.9745 \\
\hline 5 & 0.9984 & 0.9765 \\
\hline 6 & 0.9984 & 0.9810 \\
\hline 7 & 0.9979 & 0.9802 \\
\hline 8 & 0.9984 & 0.9801 \\
\hline 9 & 0.9992 & 0.9792 \\
\hline 10 & 0.9989 & 0.9815 \\
\hline 11 & 0.9980 & 0.9763 \\
\hline 12 & 0.9980 & 0.9820 \\
\hline 13 & 0.9985 & 0.9801 \\
\hline 14 & 0.9988 & 0.9793 \\
\hline 15 & 0.9987 & 0.9791 \\
\hline 16 & 0.9990 & 0.9822 \\
\hline
\end{tabular}

The voltage profile for all cases is shown in Figure3. In the 16-case voltage profile, the improvements are significant maximum and minimum voltage profiles shown in the Table III

Results of the total power loss in shows the Table III, select to input values of $Q_{j}^{C}$ are the Table I, perform the load flow program and values selection of capacitor bank in the 27 values (minimum value to maximum value). 
TABLE IV. CAPACITOR AlLOCATION AND TOTAL POWER LoSS ARE 16-CASES OF THE 37-BUS.

\begin{tabular}{|c|c|c|c|}
\hline Case & $\begin{array}{c}\text { Location } \\
\text { at Bus }\end{array}$ & $\begin{array}{c}\text { Size of C-Bank } \\
(\mathrm{kVAr})\end{array}$ & $\begin{array}{c}\text { TPL } \\
(\mathrm{kW})\end{array}$ \\
\hline 1 & 0 & 0 & 120.589 \\
\hline 2 & 7 & 3900 & 91.160 \\
\hline 3 & 13 & 3300 & 80.473 \\
\hline 4 & 17 & 2550 & 85.115 \\
\hline 5 & $5 ; 15$ & $150 ; 2400$ & 81.759 \\
\hline 6 & $8 ; 14$ & $1500 ; 2250$ & 79.416 \\
\hline 7 & $11 ; 18$ & $2550 ; 900$ & 79.534 \\
\hline 8 & $4 ; 10 ; 18$ & $600 ; 2250 ; 1200$ & 79.383 \\
\hline 9 & $8 ; 22 ; 30$ & $1800 ; 135 ; 1650$ & 80.178 \\
\hline 10 & $6 ; 13 ; 33$ & $1650 ; 1650 ; 1200$ & 79.751 \\
\hline 11 & $5 ; 8 ; 13 ; 17$ & $600 ; 1050 ; 750 ; 1200$ & 78.961 \\
\hline 12 & $6 ; 9 ; 11 ; 16$ & $900 ; 900 ; 1200 ; 1050$ & 78.723 \\
\hline 13 & $7 ; 12 ; 16 ; 31$ & $750 ; 900 ; 1250 ; 750$ & 77.889 \\
\hline 14 & $4 ; 7 ; 10 ; 14 ; 18$ & $600 ; 1050 ; 1200 ; 750 ; 900$ & 78.818 \\
\hline 15 & $12 ; 20 ; 23 ; 26 ; 36$ & $1650 ; 150 ; 750 ; 600 ; 900$ & 78.787 \\
\hline 16 & $3 ; 6 ; 9 ; 13 ; 18$ & $600 ; 300 ; 1350 ; 1500 ; 750$ & 78.256 \\
\hline
\end{tabular}

Therefore, the proposed method offers more cost saving and more loss reduction of a distribution feeder. The voltage profile for the proposed method is close to that of the 37-bus as shown in Table IV.

Table IV shows the results of the feeder 37-bus and it is observed that the total power losses for the feeder was 77.889 $\mathrm{kW}$ and loss reduction was $\$ 13,868.05$ on total annual cost before and after compensation. So, it is less than that of the total power loss and the fixed cost (the cost of the installed capacitors only) is also less than that of the proposed method.

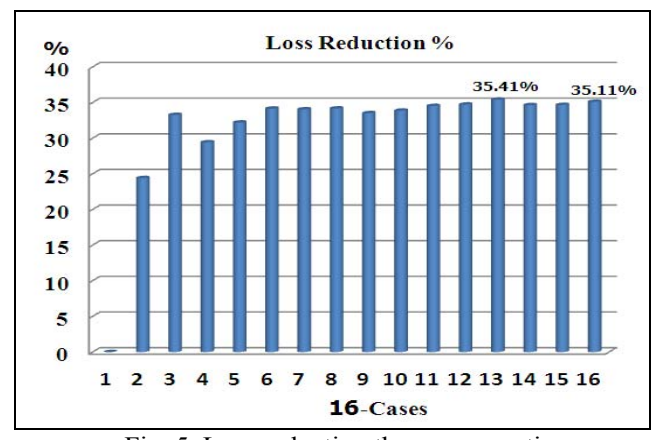

Fig. 5. Loss reduction the compensation.

From Table V, it can be seen that the proposed method offers less total power loss and less cost. Hence, it provides more cost saving and more loss reduction for a distribution feeder in Vientiane province.

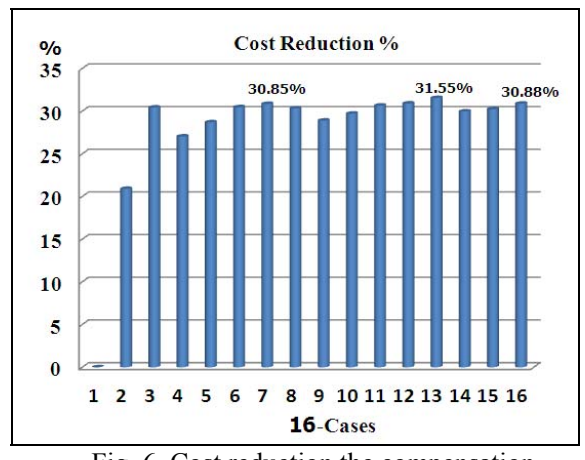

Fig. 6. Cost reduction the compensation

The 37-bus system is the best case. Fig. 5 clearly shows the loss reduction of $35.41 \%$ and Fig. 6 clearly shows the cost reduction of $31.55 \%$ on distribution feeder before and after compensation. The original case for this feeder is shown in
Table III.

\section{CONCLUSION}

The improvement of voltage drop, power loss and its cost in $22 \mathrm{kV}$ radial distribution feeder in Lao PDR is presented in this paper by optimizing location and size of the capacitor bank. It has been shown that the proposed method results are the best; which ensures the superiority of this work. Proper capacitor planning with regards to location and size of the capacitor can be used to practical distribution feeder.

\section{ACKNOWLEDGMENTS}

The authors would like to acknowledge the support of the project from the Electricity Generating Authority of Thailand (EGAT) and Electricite Du Laos (EDL) under technical-academic collaboration project between EGAT and EDL.

\section{REFERENCES}

[1] A. Coelho, C. L. C. de Castro, M. G. Da Silva, and A. B. Rodrigues, "Inclusion of voltage drop and feeder loading constraints in the evaluation of reliability indices for radial distribution networks." Generation, Transmission and Distribution, IEE Proceedings. November 2006.pp. 661-669.2006.

[2] M. M. Hamada, A. Wahab, M. El-Sayed, and A. Ramadan, "A Proposed Strategy for Capacitor Allocation in Radial Distribution Feeders," Power Systems Conference, March 2006, pp.146-151. 2006.

[3] Lao Technical Standard. Distribution Design Manual, Part B, Section 6, pp. 6-8. 2004. Available from, http:// www.edl-laos.com.

[4] A Mohammad, S. Masoum, M. Ladjevardi, A. Jafarian, and E. Fuchs, "Optimal Placement, Replacement and Sizing of Capacitor Banks in Distorted Distribution Networks by Genetic Algorithms," IEEE Transactions on power delivery, vol. 19, October 2004. Pp.1794-1801.2004.

[5] H. N. Ng, M. M. A. Salama, and A. Y. Chikhani, "CapacitorAllocation by Approximate Reasoning Fuzzy Capacitor Placement," IEEE Transaction on Power Delivery, vol. 15, No. 1, January 2000.pp. 393-397.2000

[6] R. M. Kamel and B. Kermanshahi "Optimal Size and Location of Distribution Generation for Minimizing Power Losses in a Primary Distribution Network," Computer Science and Engineering. Electrical Engineering, vol. 16, December 2009.pp.137-144.2009.

[7] C. H. Lin, C. S. Chen, T. T. Ku, and C. Y. Ho, "Mitigation of Three-phase Unbalancing for Distribution Feeders Feeders by Rephasing of Laterals and Distribution Transformers," Transmission and Distribution Conference, April 2010.pp. 1-6.2010.

[8] H. M. Khodr, I. J. Zerpa, P. M. De Oliveira-De Jesu's, and M. A. Matos, "Optimal Phase Balancing in Distribution System Using Mixed-Integer Linear programming," Transmission and Distribution Conference, August 2006.pp.1-5.2006.

[9] W. Hsieh, C. Lin, C .C hen, C. T. Hsu, T. Ku, C. Tsai and C. Ho, "Impact fo PV Generation to Voltage Variation and Power Losses Of Distribution Systems," Electric Utility .DRPT. International Conference. July 2011. pp.1474-1478.2011.

[10] F. C. V. Malange, D. A. Alves, L. C. P. da Silva, C. A Castro, and G. R. M. da Costa, "Real Power Losses Reduction and Loading Margin Improvement via Continuation Method," IEEE Transactions on power system, vol. 19, August 2004.pp.1690-1692.2004.

[11] R. Srinivasa Rao and S. V. L. Narasimham, "Optimal Capacitor Placement in a Radial Distribution System using Plant Growth Simulation Algorithm", World Academy of Science, Engineering and Technology 2008.pp.714-722.2008.

[12] S. F. Mekhamer, S. A. Soliman, M. A. Moustafa, and M. E. El-Hawary, "Application of Fuzzy Logic for Reactive-Power Compensation of Radial Distribution Feeders," IEEE Transactions on power system, vol. 18, February 2003.pp.206-213.2003.

[13] C. T. Zong SU, G. RURNG LII, and C. CHENG TSAI, "Optimal Capacitor Allocation Using Fuzzy Reasoning and Genetic Algorithms for Distribution Systems", Mathematical and Computer Modeling, vol. 33, March 2001.pp.745-757.2001. 


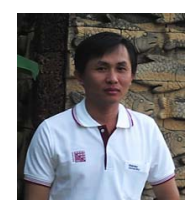

Khamphoungurn TILAKUL Received a Bachelor's degree of Electrical engineering at National University, Lao in 2000. He is presently working at BVP Department in Electricite Du Laos (EDL) and studying Master of electrical engineering at Khon Kaen University.

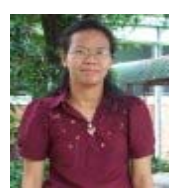

Panhathai Buasri received her. B. Eng. in Electrical Engineering from Khon Kaen University, Thailand in 1996. She received her .M.S. and D. Eng from the University of Massachusetts, Lowell. Her research interests include power system and renewable energy sources.

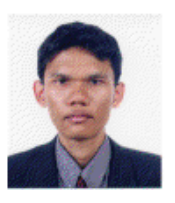

Arkom Kaewrawang received B. Eng. fromKhon Kaen University, Khon Kaen, Thailand in 2001, M. Eng. from Chulalongkorn University, Bangkok, Thailand in 2003 and Ph.D. degree from Shinshu University, Nagano, Japan in 2010. At present he is a full time Assistant Professor at Khon Kaen University, Khon Kaen, Thailand.

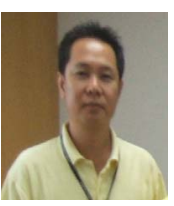

Jittipath Triyangkulsri was born in Nakhon Phanom, Thailand. He received B.Eng. in electrical engineering and M.Eng. in electrical and system engineering from Khon Kaen University, Thailand. $\mathrm{He}$ is a system dispatcher at Northeastern Dispatching Center, Electricity Generating Authority of Thailand (EGAT). $\mathrm{He}$ is interested in advanced power system control. 